\title{
Mineral Interfaces and Oil Recovery: A Microscopic View on Surface Reconstruction, Organic Modification, and Wettability Alteration of Carbonates
}

Ashit Rao,* Saravana Kumar, Carla Annink, Duy Le-Anh, Subhash C. Ayirala, Mohammed B. Alotaibi, Igor Siretanu, Michel H.G. Duits, Ali A. Yousef, and Frieder Mugele*

Cite This: Energy Fuels 2020, 34, 5611-5622

Read Online

ACCESS | Lلll Metrics \& More | 回 Article Recommendations | st Supporting Information

ABSTRACT: While it is generally known that aging protocols have an important impact on the interaction between crude oil (CRO), brines, and mineral surfaces, the microscopic consequences of the various steps of aging have hardly been described. In this study, we characterize the properties of fluids and carbonate mineral surfaces throughout a series of equilibration steps at $95{ }^{\circ} \mathrm{C}$ and correlate these microscopic observations with macroscopic contact angle measurements. Chemical equilibration of $\mathrm{CRO}$ (eqCRO) and FW (eqFW) leads to transfer of organic molecules from the former to the latter, causing also a pH change in the eqFW. Confocal Raman microscopy, atomic force microscopy, and infrared spectroscopy are used to reveal how consecutive aging of calcite in eqFW and eqCRO induces: first, in eqFW, considerable surface reconstruction and precipitation of mineral particles with colocalized organic species, and second, upon exposure to eqCRO, the formation of a second adlayer primarily composed of polyaromatic hydrocarbon-rich particles. Our results show how these interconnected microscopic chemical and topographical surface modifications give rise to more "oil wetting" contact angles after the two-step aging procedure.

\section{INTRODUCTION}

Carbonate reservoirs hold more than half of the Earth's oil, ${ }^{1}$ an important energy resource for this century. However, recovering the large amounts of residual oil in carbonate reservoirs after primary and secondary recoveries, remains a strong challenge. The difficulty lies in the complex interplay between geochemical and mineralogical factors such as inhomogeneous wettability ranging from oil-wet to mixed wet conditions, intricate microporous structures, and high fracture densities. ${ }^{2-6}$ This problem is currently met by individual or combinative applications of improved oil recovery (IOR) strategies, encompassing low-salinity brine injection, chemical flooding, miscible flooding, and thermal flooding. ${ }^{7,8}$ These technologies have sparked an enormous interest to identify the mechanism(s) underlying IOR. However, the fundamental nano- and microscale petrophysical aspects of carbonate minerals as well as their contributions in determining wettability alterations and fluid displacement remain unclear. A detailed understanding of reservoir pertinent interfaces is an important prerequisite to address the in situ dynamics of mineral-oil-brine systems and also to enable the laboratory development and rational deployment at reservoir scales of IOR strategies.

Processes of oil recovery portray a multiscale structure, ranging from nanoscale interactions between molecules, ions, droplets, and crystal sites, to fluid displacement and fine migration within the microporous structure, to the Darcy scale, and subsequently to the reservoir scale across kilometers., 3,9 Within this hierarchy, nano- and microscale interactions between mineral interfaces and fluidic phases determine mineral wettability and consequently the success of IOR.
Note that we use the term "wettability" in the sense of physical chemistry, i.e., as an equivalent of "contact angle" on a flat surface. For low-salinity IOR in carbonate reservoirs, proposed microscopic mechanisms include mineral dissolution, ${ }^{10}$ double layer expansion, ${ }^{11}$ contributions of $\mathrm{SO}_{4}{ }^{2-}$ ions from anhydrite dissolution, ${ }^{12,13}$ salinity-related changes in the mineral-brine and oil-brine surface charges ${ }^{14-17}$ as well as the desorption of ionic-organic layers from mineral surfaces. ${ }^{18}$ As a consequence of this multiplicity, the primary mechanism of IOR and possible contributions from synergistic or secondary mechanisms often remain ambiguous. Any attempt to establish the relevance of a specific microscopic mechanism, however, depends on the preparation of a well-defined and representative initial condition of the mineral and the fluids involved. Therefore, the surface chemistry and topography of carbonate minerals are key aspects for understanding IOR. ${ }^{19}$ In developing a reservoir relevant model system with analogous chemical and topographical properties, multiple factors require attention. First, carbonate minerals are dynamic in nature, undergoing dissolution, recrystallization, and transformation in response to ambient fluids as well as temperature and pressure. $^{20-26}$ Second, crude oil (CRO) is a heterogeneous and complex substance, with more than a million components,

Received: January 10, 2020

Revised: April 6, 2020

Published: April 6, 2020 
encompassing chemical classes such as $n$-alkanes (paraffins), branched alkanes (iso-paraffins), alkenes (olefins), branched alkenes (iso-olefins), cyclic alkanes (naphthenes), and several aromatic types. ${ }^{27-29}$ Although the adsorption of organic species from CRO to the mineral is generally considered as the main reason for the "oil-wet" character of reservoirs, neither the precise nature of these surface active species nor their organization at mineral-oil-brine interfaces is well understood. $^{18,19,30}$ For instance, organic molecules such as asphaltenes, resins, kerogens, and carbazoles are identified as adsorbents on mineral surfaces; however, the related intermolecular interactions and interface structure are unclear. In addition, certain polar and nonpolar constituents of CRO can migrate to the aqueous phase, ${ }^{31,32}$ affecting the composition and physical properties of brines. The third aspect is the diagenesis (physical and chemical modifications) of mineral phases in CRO and native water pools, which influence the wettability, porosity, and permeability of reservoirs.

The replication of the chemical diversity and metastable conditions within reservoirs are important elements of models at the mineral to pore scales. While simple model systems such as fatty acids and asphaltenes have shed some light on adsorption and self-assembly processes, ${ }^{33-35}$ they miss the synergistic relations involving diverse organic and ionic constituents of reservoirs fluids as well as the diagenetic changes of minerals. On the contrary, full-complexity reservoir fluids have demonstrated wettability alteration toward more oil-wet after CRO exposure and, at the same time, pointed to the relevance of aging conditions such as temperature and fluid compositions. ${ }^{36,37}$ The nature of the relevant microscopic physiochemical processes, however, such as mineral restructuration, deposition of organic molecules, and the structure and composition of the resulting mineral interfaces have not been systematically addressed.

The main objective of this work is to identify which microscopic changes occur during fluid equilibration and the exposure of calcite to different fluids, under reservoir mimetic conditions. Additionally, we examine the consequences of these microscopic changes for the macroscopic wettability. To the best of our knowledge, the equilibration of CRO and $\mathrm{FW}^{31}$ and surface modification of calcite by reservoir-related heterogeneous fluids ${ }^{18}$ have only been independently addressed. By integrating these approaches, we provide holistic physical insights into the dynamics of the mineral-oil-brine systems that subsequently underlay the chemical and topographical modifications of minerals. Microscopic analyses of carbonate surfaces by confocal Raman and atomic force microscopy after each step in the history of their exposure to equilibrated fluids address the microscopic mechanisms underlying the macroscopic wettability of minerals.

\section{EXPERIMENTAL SECTION}

Materials. Mineral samples utilized in the experiments were freshly cleaved Iceland spar (Ward's Science) and calcite powders (Sigma-Aldrich). Batches of dead crude oil (CRO) samples were obtained from a carbonate reservoir. Summarized in Table 1 are the characterization of CRO batches, as performed by a certified laboratory at Saybolt Nederland B.V., and the viscosity, as measured with a Haake RS600 controlled stress rheometer using a Couette geometry.

Artificial formation water (referred to as "FW" or "unaged FW") was prepared by mixing Sigma-Aldrich reagent grade chemicals (sodium chloride, magnesium sulfate, calcium chloride, magnesium
Table 1. Physicochemical Characteristics of Crude Oil

$\begin{array}{lll}\text { viscosity }\left(\text { at } 21.5{ }^{\circ} \mathrm{C}\right) & 18 & \mathrm{mPa} \cdot \mathrm{s} \\ \text { acid number } & 0.2 \pm 0.04 & \mathrm{mg} \mathrm{KOH} / \mathrm{g} \\ \text { base number } & 1.1 \pm 0.1 & \mathrm{mg} \mathrm{KOH} / \mathrm{g} \\ \text { asphaltenes } & 2.6 \pm 0.3 & \mathrm{mass} \% \\ \mathrm{C} 10+ & 91 \pm 3.3 & \mathrm{mass} \% \\ n \text {-heptane } & 0.9 \pm 0.4 & \text { mass\% } \\ n \text {-octane } & 1.0 \pm 0.2 & \text { mass\% } \\ n \text {-hexane } & 0.6 \pm 0.5 & \text { mass\% }\end{array}$

chloride, and sodium bicarbonate) with deionized water (18.2 $\mathrm{M} \Omega$ $\mathrm{cm}$, Milli-Q), to achieve the ion composition listed in Table S1. The aqueous suspension was stirred overnight at room temperature and filtered through a PES filter membrane $(0.2 \mu \mathrm{m})$.

Formation Water-Crude-Oil Equilibration. To mimic the equilibration of fluids within reservoirs, equal parts $(125 \mathrm{~mL}$ each) of FW and CRO were equilibrated in a sealed glass bottle $(500 \mathrm{~mL})$ at $95{ }^{\circ} \mathrm{C}$ for a period of $48 \mathrm{~h}$. Prior to equilibration, a few Iceland spar chips were added to the mixture (to maintain brine $\mathrm{pH}$ ) and the calcite-brine-oil mixture was degassed for $20 \mathrm{~min}$ in a desiccator. To facilitate solute transfer between the liquids while avoiding emulsion formation, only intermittent gentle shaking was applied during the equilibration. After cooling to room temperature, the equilibrated brine ("eqFW") and oil ("eqCRO") phases were isolated with a separating funnel and stored in sealed glass containers.

Surface Modification of Calcite. Surface modification of freshly cleaved Iceland spar crystals was performed in a sequential manner at $95^{\circ} \mathrm{C}$, initially in eqFW for $16 \mathrm{~h}$ and then in eqCRO for 7 days. Prior to each of the high-temperature incubations, the respective fluid with immersed calcite was briefly degassed in a vacuum desiccator to prevent air bubbles that inhibit fluid contact during aging. Preceding surface characterization and wettability studies, the eqFW-aged crystals were briefly rinsed with DI water to avoid the evaporative deposition of salt, whereas the eqCRO-aged crystals were gently cleaned with a toluene stream dispensed from a needle (inner diameter $1.54 \mathrm{~mm}$ ) to remove adherent oil residues. Modified in this manner, the calcite samples were allowed to dry in a fume hood and were stored in a nitrogen compartment. Similar protocols were used for calcite powders (Figure S1).

Molecular and Microscopic Characterizations. Absorbance and fluorescence spectra of equilibrated brines were acquired using a Shimadzu UV-2401 UV-visible spectrophotometer and a Tecan infinite M200 pro plate reader, respectively. The surfaces of (modified) Iceland spar substrates were characterized using a variety of techniques. X-ray photoelectron spectroscopy (XPS) was performed with a Quantera SXM from Physical Electronics. Scanning electron microscopy (SEM) was done with a Zeiss MERLIN HRSEM. Prior to SEM, the samples were coated with a thin layer of chromium by using an Emitech sputter coater. Atomic force microscopy (AFM) imaging via amplitude modulation was performed at a rate of $0.5 \mathrm{~Hz}$ with resolutions of $512 \times 512$ in air using NSC36 probes (MikroMasch) and a Bruker Dimension Icon instrument.

Confocal Raman microscopy (CRM) was performed using a WiTec alpha $300 \mathrm{R}$ instrument equipped with a $532 \mathrm{~nm}$ laser. A grating of $600 \mathrm{~g} / \mathrm{mm}$ provided a spectral resolution of $2.3 \mathrm{~cm}^{-1}$. A $50 \times$ objective (Zeiss EC Epiplan, Numerical Aperture $=0.75$ ) and a CCD camera $(1600 \times 200$ pixels, $16 \mu \mathrm{m}$ pixel size, Andor Newton $)$ were used. Spectral data sets were baseline corrected using the Witec ProjectFIVE software, and subsequently, principal component analysis (PCA) guided denoising was applied (Figure S2). Raman maps were generated by integrating the spectral regions of interest for every pixel: from 1076 to $1095 \mathrm{~cm}^{-1}$ for calcite $\left(\nu_{1}\right.$, in-plane bending), 1500 to $1650 \mathrm{~cm}^{-1}$ for polyaromatic hydrocarbons ( $G$ and $D 2$ bands), and 200 to $225 \mathrm{~cm}^{-1}$ for aragonite (lattice mode). Fourier transform infrared (FTIR) spectra of calcite powders were obtained with a Bruker ALPHA spectrometer operated in attenuated total reflection mode. 

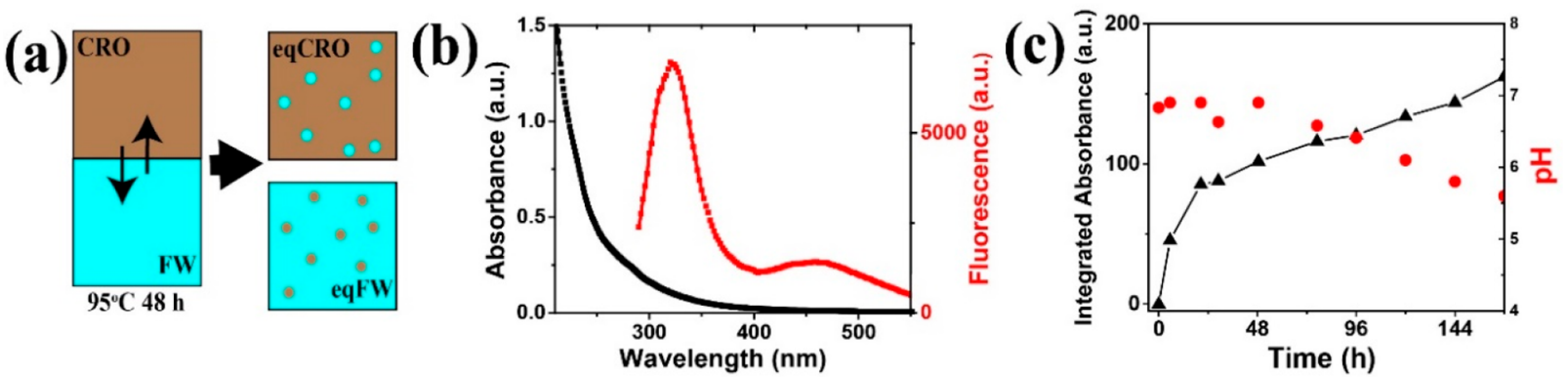

Figure 1. (a) Schematic representation of FW and CRO equilibration wherein equal parts of the brine and oil phases are kept in mutual contact at high temperature. (b) Absorbance (black) and fluorescence (red, excitation wavelength: $260 \mathrm{~nm}$ ) spectra of FW after $48 \mathrm{~h}$ equilibration. (c) Evolutions of the absorbance (black, integrated from 210 to $450 \mathrm{~nm}$ ) and $\mathrm{pH}$ (red) of FW during equilibration with CRO.

Contact Angle Measurements. Contact angle goniometry was used to characterize the wettability of (modified) Iceland spar surfaces in ambient eqFW at room temperature. Contact angles of eqCRO droplets were estimated by using a goniometer (Dataphysics OCA 20L) via the captive bubble method. The steel needle of the droplet dispensing module contained eqCRO and was immersed in eqFW in a glass cuvette (Hellma Analytics). After introducing the substrate in the ambient brine, a dwell time of 30 min was given for equilibration. The experiment was started by depositing a $5 \mu \mathrm{L}$ droplet of eqCRO on the substrate. After $30 \mathrm{~min}$, the eqCRO droplet was infused at a rate of $0.015 \mu \mathrm{L} / \mathrm{min}$ to a final volume of $20 \mu \mathrm{L}$, during which the advancing oil contact angle $\left(\theta_{\mathrm{oil}}^{\mathrm{adv}}\right)$ was measured. The receding contact angles $\left(\theta_{\text {oil }}^{\text {rec }}\right)$ were systematically much lower and could not be accurately estimated. The $\theta_{\text {oil }}^{\text {adv }}$ values for several droplets and subtrates for each surface modification approach are reported and are representative of about 2-3 droplets for each calcite sample.

\section{RESULTS AND DISCUSSION}

Toward Reservoir Pertinent Fluids: CRO-FW Equilibration. To generate brine and oil compositions representative of reservoir fluids, FW and CRO were equilibrated at 95 ${ }^{\circ} \mathrm{C}$. During this process, the transfer of organic molecules from CRO to the formation brine occurs, as illustrated in Figure 1a. The mass transfer after $48 \mathrm{~h}$ is evident from an increased absorbance in the near-UV range and from the peaks at 322 and $460 \mathrm{~nm}$ in the fluorescence emission spectrum of eqFW (Figure 1b). The near-UV absorbance of the eqFW indicates the presence of aromatic hydrocarbons, while the absorbances from 210 to $450 \mathrm{~nm}$ suggest a heterogeneous organic composition with aromatic and heterocyclic hydrocarbons. ${ }^{31}$ This is supported by the fluorescence emission peak at about $322 \mathrm{~nm}$, which is characteristic of naphthalenes and their alkyl modifications. ${ }^{38,39}$ Formation water and injection brines thus acquire significant amounts of organic species in native geological and water flooding conditions, respectively.

Previous studies identified short chain alkanes and aromatic and heterocyclic hydrocarbons in the water-soluble fractions of CRO specimens. ${ }^{31,40}$ However, the existence of these organics as individual species or coassociated complexes in the equilibrated aqueous phase remained unresolved. Here, it is worth mentioning that in another study, the broad peak at 460 $\mathrm{nm}$ (similar to Figure 1b) has been associated with heterocomplexes of naphthalenes with cyclodextrin and histidine. ${ }^{41,42}$ Also the solubility enhancement of poorly or insoluble hydrocarbons by complexation with organic acids has been reported. ${ }^{43,44}$ The fluorescence peak at $460 \mathrm{~nm}$ thus suggests the phase transfer of certain organic species from $\mathrm{CRO}$ to brine as heterocomplexes containing otherwise poorly water-soluble moieties.
To further characterize the chemical functionalities of the organic species migrating to the brine, FTIR spectroscopy of oven-dried precipitates obtained from eqFW was performed (Figure S3; Table S2). The IR spectrum presents bands of polar functional groups such as alcohols, as well as intense $\mathrm{C}=$ $\mathrm{C}$ stretching bands $\left(1611\right.$ and $1627 \mathrm{~cm}^{-1}$ ) indicative of alkenes or aromatic hydrocarbons. Multifunctional brine-soluble CRO constituents and heterocomplexes are thus involved in the phase transfer of organic species to the oil-brine interface and the bulk brine. Factors underlying phase transfer include not only individual molecular parameters such as partition coefficient, ionization state, hydrophobicity, and polarity ${ }^{32}$ but also intermolecular interactions that affect the stability of heterocomplexes in aqueous and oil environments.

The total organic content of the eqFW is estimated in terms of humic acid equivalents on account of similarities in their absorbance spectra (Figure 1b; Figure S4). After $48 \mathrm{~h}$ equilibration with $\mathrm{CRO}$, the eqFW presents a humic acid equivalent of about $31 \mathrm{mg} / \mathrm{L}$ (Figure S4). The near-UV absorbance and $\mathrm{pH}$ of $\mathrm{FW}$ are also monitored during the equilibration (Figure 1c). The absorbance increases over time and does not present indications of saturation even after 1 week. Meanwhile, the $\mathrm{pH}$ depicts a gradual decrease over the equilibration period beyond $48 \mathrm{~h}$ (Figure 1c). These ongoing changes suggest (1) the slow phase transfer of acids from the crude oil to the brine phase and their deprotonation as well as (2) the gradual complexation of organic acids by metal ions as solute clusters, represented by

$$
\begin{aligned}
& \mathrm{RCOOH}_{\text {oil }} \rightarrow \mathrm{RCOO}_{\text {brine }}{ }^{-}+\mathrm{H}_{\text {brine }}{ }^{+} \\
& 2 \mathrm{RCOOH}+\mathrm{M}^{2+} \rightleftharpoons\left(\left(\mathrm{RCOO}^{-}\right)_{2} \mathrm{M}\right)_{\mathrm{aq}}+2 \mathrm{H}^{+}
\end{aligned}
$$

Based on the $\mathrm{p} K_{\mathrm{a}}$ values and partition coefficients of amphiphilic molecules, the $\mathrm{pH}$ development of the aqueous phase has been modeled by using fatty acids and bases in simple oil-water systems. ${ }^{32}$ Additionally, the aqueous solubility of hydrocarbons such as fatty acids is determined by molar mass, polarity, and temperature. ${ }^{45}$ In our case, for extended periods of FW-CRO equilibration, the accumulation of microscopic particles in the brine phase is also observed (Figure S5). Hence the chemical equilibria associated with the FW-CRO equilibration process should be extended to incorporate the nucleation and growth of metal-organic particles, represented as

$$
\left(\left(\mathrm{RCOO}^{-}\right)_{2} \mathrm{M}\right)_{\mathrm{aq}} \rightarrow\left(\left(\mathrm{RCOO}^{-}\right)_{2} \mathrm{M}\right)_{\text {solid }}
$$

In consideration of these chemical processes, a hypothetical steady state would represent the depletion of free metal ions in 

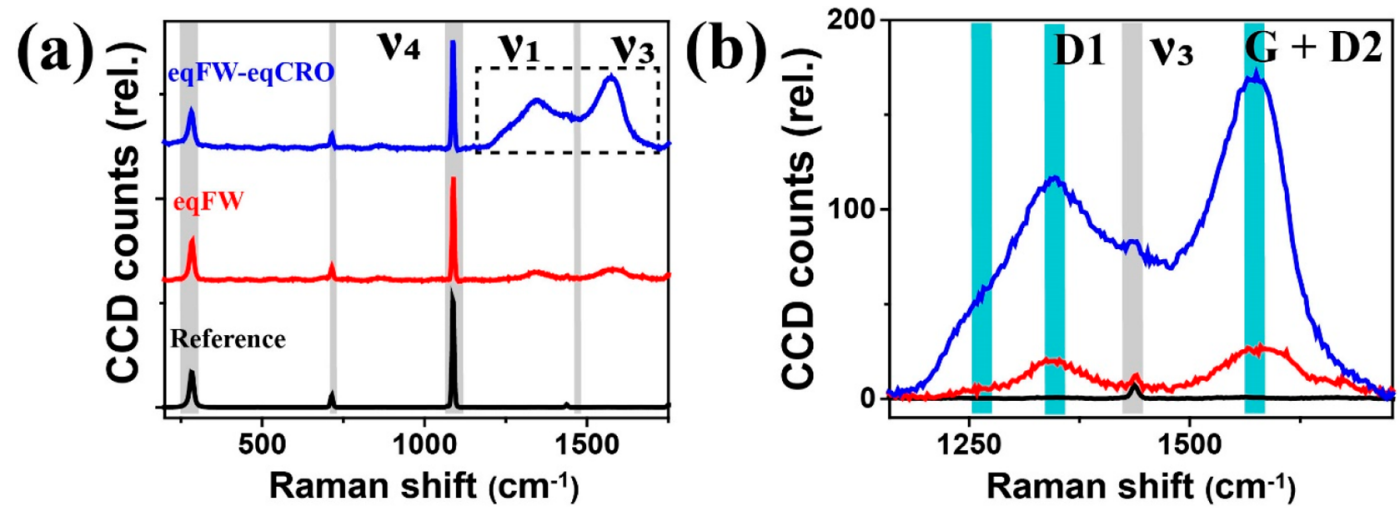

Figure 2. ( $a, b)$ Representative baseline-corrected spectra of bare calcite (black), eqFW (red), and eqFW- and eqCRO-treated (blue) Iceland spar, with peaks specific to Raman active modes of calcite (gray regions). (b) Peaks corresponding to organic species (cyan regions) represent D1 (1355 $\left.\mathrm{cm}^{-1}\right)$ and $\mathrm{G}$ and $\mathrm{D} 2\left(1570 \mathrm{~cm}^{-1}\right)$ bands for polyaromatic hydrocarbons.

the brine phase, the depletion of water-soluble constituents in the CRO phase, or the saturation of the brine phase by watersoluble CRO constituents. In this regard, the observed lack of steady state can emerge as a result of the abundance of ionic species in FW (Table S1) and significant contents of water miscible organic species in the CRO phase. Moreover, the gradual decrease in brine $\mathrm{pH}$ during $\mathrm{CRO}-\mathrm{FW}$ equilibration can influence the ionization states of CRO-derived molecules, thereby imparting $\mathrm{pH}$ dependent phase transfer tendencies. In this respect, augmented phase transfer of pyridinic nitrogen functionalities from $\mathrm{CRO}$ to brines of low $\mathrm{pH}$ has also been reported. ${ }^{31}$ Here, it is noteworthy that the organics, having undergone phase transfer, can exist as either solutes or particulates, primarily depending on their limits of solubility.

In carbonate reservoirs, the microstructure and composition of minerals, respectively, produce a high surface to volume ratio and a buffering capacity involving (bi)carbonate species, which together might suppress the severe acidification of connate water and injection fluids during interactions with CRO. ${ }^{17}$ Given the lack of steady state concerning the migration of organic molecules from CRO to FW and the accumulation of metallo-organic solids in the brine phase on prolonged equilibration, fluids equilibrated for periods of $48 \mathrm{~h}$ are utilized for further experiments addressing the surface modifications and wettability of calcite.

Previous studies addressing the wettability alterations of calcite and rock samples after CRO exposure show that prolonged aging and high temperature are essential for getting adequate "oil-wet" responses. ${ }^{36,46}$ To replicate the related mineral-fluid interactions, the eqFW and eqCRO are sequentially applied for the surface modification of Iceland spar at $95{ }^{\circ} \mathrm{C}$ for extended periods. Before and after each step of fluid treatment, mineral surfaces are analyzed with CRM, AFM, and FTIR spectroscopy to characterize the emergent surface chemistry and topography.

Chemical Modifications of Calcite. As shown in Figure 2a, the location-averaged Raman spectrum of bare Iceland spar presents peaks at 157 and $282 \mathrm{~cm}^{-1}$, corresponding to the lattice modes of calcite, and peaks at 713 and $1085 \mathrm{~cm}^{-1}$, representing $\nu_{4}$ (in-plane bending) and $\nu_{1}$ (symmetric) internal modes of carbonate species, respectively. ${ }^{47}$ For eqFW- and eqCRO-aged calcite substrates (Figure 2b), additional peaks are found at 1355 and $1570 \mathrm{~cm}^{-1}$. These frequency bands represent graphitic hydrocarbons, with the $\mathrm{G}$ band (1570 $\mathrm{cm}^{-1}$ ) indicative of $\mathrm{sp}^{2} \mathrm{C}-\mathrm{C}$ stretching vibrations within aromatic organizations, and the D1 band $\left(1355 \mathrm{~cm}^{-1}\right)$ indicative of in-plane defects or substitutions, which affect the vibrational modes of the $\mathrm{sp}^{2} \mathrm{C}-\mathrm{C}$ bond. ${ }^{48}$ Studies also report a D2 vibrational mode present as a shoulder to the $\mathrm{G}$ band, indicative of the edge structure of proximal aromatic molecules. ${ }^{49}$ For calcite samples exposed to eqCRO, the Raman spectra also show a shoulder at $\sim 1260 \mathrm{~cm}^{-1}$, representing $\mathrm{CH}_{2}$-related vibrations. ${ }^{50}$

The D1, G, and D2 modes are typical for reservoir-related polyaromatic hydrocarbons (PAHs) like asphaltenes and kerogens. $^{51,52}$ Asphaltenes encompass a complex family of PAHs, displaying considerable heterogeneity in terms of aromatic configurations and contents of oxygen, nitrogen, or sulfur. ${ }^{53}$ The presence of PAHs at the mineral interface after eqFW exposure clearly indicates that organic modifications of mineral surfaces can occur in CRO-equilibrated brine phases. Given the solubility of the surface-active species in FW (Figure 1b), some polar moieties could also contribute to the electrostatic forces involved in acid-base or ion bridging interactions that underlay the surface modification of minerals.

Subsequent exposure of the Iceland spar to eqCRO leads to significantly higher intensities of the D1, G, and D2 bands (Figure 2b). This more prominent deposition of PAHs from eqCRO can result from multiple factors such as the abundance of asphaltenes in the CRO (Table 1), the distinct aggregation states of asphaltenes in $\mathrm{CRO},{ }^{54}$ and also the preconditioning of calcite by eqFW treatment. While previous studies demonstrated the adsorption onto calcite of solvent extracted PAHs such as asphaltenes, ${ }^{55,56}$ we show here that the surface modification by polyaromatic molecules such as asphaltenes can occur via contact with equilibrated brine and CRO phases. The latter pathway should correspond more closely to the processes taking place in the reservoir. We remark here that the toluene washing applied after the exposure to eqCRO may have influenced the morphology of organic deposits.

After considering the averaged Raman spectra, we now focus on the spatial distribution of the different materials on the calcite substrates. While revealing such information is the key ability of CRM, an enhanced signal processing is needed. In case of Iceland spar, not only the instrumental noise but also a strong fluorescence background (absent for synthetic calcite) has to be taken into account (Figure S6). This fluorescence can originate from organic molecules, either occluded in the mineral structure or as atmosphere-derived carbonaceous matter. ${ }^{57}$ The XPS spectra taken of our Iceland spar samples 


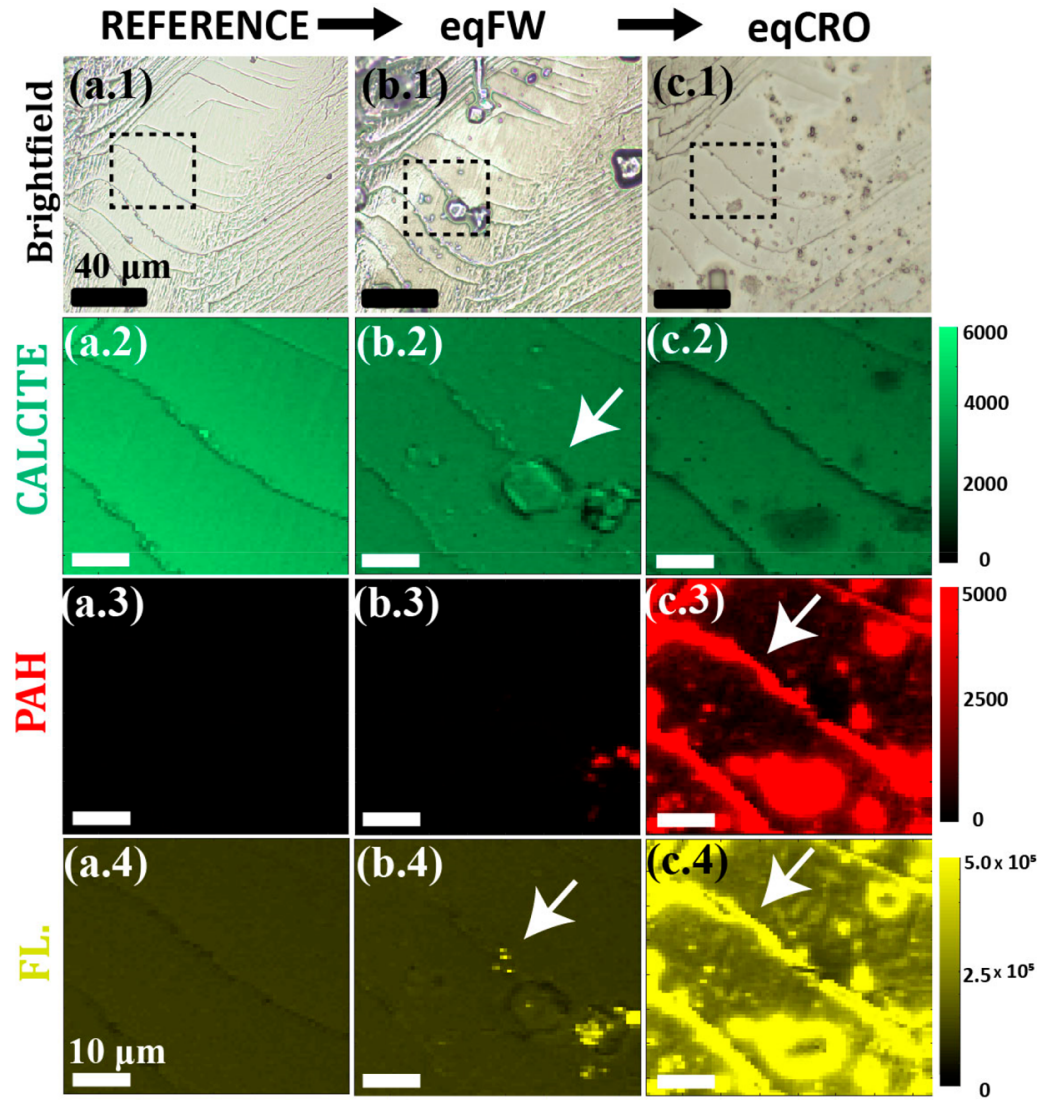

Figure 3. Bright field microscopy- (top row) and CRM-derived $x-y$ false color images representing the distributions of calcite, polyaromatic hydrocarbons (PAH), and fluorescence (FL.) for Iceland spar before aging (reference) and after sequential exposure to eqFW and eqCRO. Boxed areas (top row) are mapped using a step size of $0.66 \mu \mathrm{m}$ in $x$ and $y$ directions. Scale bars represent $40 \mu \mathrm{m}$ (bright field images) and $10 \mu \mathrm{m}$ (distribution maps).

indeed show evidence for such organic constituents (Figure S6). Furthermore, some metal ions occluded within calcite can induce fluorescence. ${ }^{58}$ In our data analysis, we not only corrected for the inherent fluorescence via a baseline subtraction but also used the thereby generated residuals for localizing the fluorophores. Besides that, contributions from instrumental noise were minimized via a principal component analysis (PCA) guided data denoising algorithm (Figure S2). ${ }^{59}$ The resulting Raman maps for calcite and $\mathrm{PAH}$, along with fluorescence and brightfield images, are shown in Figure 3.

At the microscale, the reference and aged Iceland spar substrates present terraces and macrosteps as topographical features (top row, Figure 3). These structural markers enable tracking of the Iceland spar substrate by CRM at consistent locations after each aging step. Image reconstruction from spectral data sets is based on intensity variations of the respective bands of interest in the $x-y$ plane (i.e., parallel to the calcite-air interface). Considering the distribution maps of calcite after exposure to eqFW, several asperities and particle deposits are observed compared to the original substrate (Figure 3b.2). Given the retrograde solubility of calcite, i.e., decrease of mineral solubility with increasing temperature, ${ }^{60}$ the nucleation and growth of calcite from the synthetic formation water are anticipated at elevated temperatures. As shown in Figure 3b (arrows), these sites of reconstruction on mineral surfaces accumulate polyaromatic and fluorescent components, indicating an interplay between mineral dissolution-precipitation and the surface deposition of organic molecules. Note that the distributions of fluorescence and $\mathrm{PAH}$ do not strongly correlate, indicative of structural heterogeneity within the ensemble of polyaromatic adsorbents. For instance, ring substitutions and size of aromatic chromophores of PAHs such as asphaltenes can considerably shift fluorescence emission and absorption maxima. ${ }^{61}$

For eqCRO-aged Iceland spar substrates, the spatial distributions of $\mathrm{PAH}$ and fluorescence across the calcite surface are nonuniform, with preferential deposition at the macrosteps (Figure 3c, arrows). From the literature, it is known that certain organic and inorganic species can adsorb on these active sites, suppressing further crystal growth or undergoing incorporation in the mineral structure. ${ }^{62-64}$ Such crystal modification mechanisms are also evident in Figure 3, where CRO-derived organic molecules are seen to accumulate at calcite macrosteps. Surface features such as steps and kinks thus affect the local deposition of organic molecules including PAHs and fluorophores. Similar processes might lead to the creation of reservoir rocks with mixed wettability, ${ }^{65}$ where grains with high surface defect density recruit more organic species and are more oil-wet than grains with fewer defect sites. Note that the deposition of organic molecules is favored at but not restricted to the macrosteps; it also occurs at relatively flat crystalline surfaces (Figure S7).

The calcite substrates are further characterized by CRM, using a depth profiling approach. Large area scans were performed in the $x-z$ plane (i.e., perpendicular to the calciteair interface) to generate the intensity profiles of calcite, PAHs, 

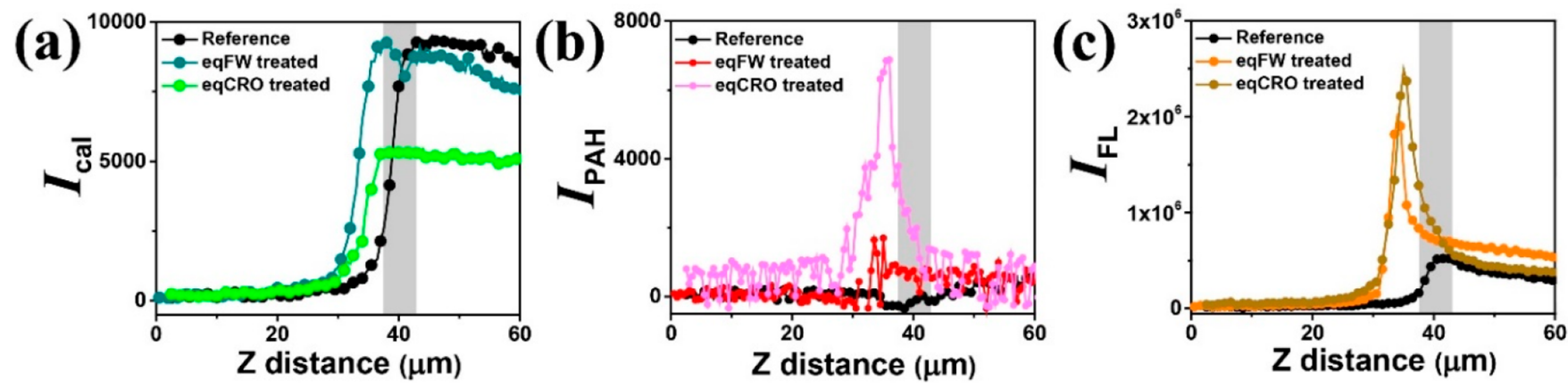

Figure 4. Intensity plots of (a) calcite, (b) PAH, and (c) fluorescence across air-calcite interfaces as a function of depth within the sample, for reference Iceland spar and after subsequent surface modifications with eqFW and eqCRO. Aging calcite in eqFW produces an inflection in $I_{\text {cal }}$, indicative of mineral overgrowth (gray boxes).

and fluorescence, shown in Figure 4 and Figure S8. The calcite signals are shown in Figure 4a. For the eqFW-aged Iceland spar, the intensity profile shows an inflection, which might represent the deposition of mineral layers during prolonged aging at $95{ }^{\circ} \mathrm{C}$. Remarkably, for the eqCRO-aged crystals, the intensities for calcite are significantly lower than for bare Iceland spar. This is ascribed to an attenuation of light by the adlayer enriched with polyaromatic molecules and fluorophores (Figure 3).

The intensity profiles in Figures $4 b, c$ show the accumulation of polyaromatic and fluorescent molecules, respectively. While the reference Iceland spar presents some intrinsic fluorescence, the surface deposition of organic species from eqFW and eqCRO clearly produces augmented fluorescence restricted to the mineral surfaces. Also, the $\mathrm{PAH}$ signal indicates the material accumulation to be exterior, albeit that in this case, the eqCRO signal is much stronger than that of eqFW. This accumulation of organic matter at mineral grain boundaries is consistent with observations of rock specimens. ${ }^{66}$ Clearly, the microscale modifications of minerals surfaces by equilibrated fluids are both topographical and chemical in nature.

Note that the Raman signal is proportional to not only the abundance of scattering molecules but also the scattering crosssection. This introduces a strong sensitivity (intrinsic bias) toward conjugated molecules, ${ }^{67}$ thereby potentially obscuring smaller, e.g., aliphatic, molecules. To examine the presence of the latter species with higher accuracy, we performed FTIR spectroscopy on synthetic calcite powders treated with eqFW and eqCRO at $95{ }^{\circ} \mathrm{C}$ (Figure S1). Using this calcite, contributions of intrinsic fluorescence are avoided as well (Figure S6). Complementary to Figure 2, the FTIR spectra are used to identify the chemical functionalities of organic molecules binding to calcite surfaces (Figures S9 and S10). Band assignments are performed in accordance with the literature values ${ }^{68}$ (as summarized in Tables S4-S6).

For eqFW-aged calcite, the IR spectra exhibit bands indicative of alkenes as well as polar modifications such as alcohols or amines. This portrays that the calcite binding organic molecules in eqFW incorporate several functional groups, suggestive of either hydrocarbons with oxygen and nitrogen substitutions or heterocomplexes of hydrocarbons and polar molecules. In relation, the IR spectra of eqCRO-aged calcite present distinct aliphatic and aromatic $\mathrm{C}-\mathrm{H}$ stretching bands in the range of $2800-3100 \mathrm{~cm}^{-1}$. As summarized in Table S6, the peak positions correspond to the symmetrical and asymmetrical stretching of the aromatic and aliphatic hydrogens, representative of asphaltenic molecules. ${ }^{69}$ In summary, the results of Raman and IR spectroscopy show that multiple organic species such as graphitic hydrocarbons and polar molecules contribute to the surface modification of calcite by reservoir pertinent fluids (Table 2).

Table 2. Summary of Peak Positions for Raman and IR Active Organic Species for eqFW- and eqCRO-Aged Calcite

\begin{tabular}{|c|c|c|}
\hline & eqFW-aged & eqCRO-aged \\
\hline \multicolumn{3}{|c|}{ Raman spectroscopy } \\
\hline $\begin{array}{l}\text { G band (graphitic } \\
\text { hydrocarbons) }\end{array}$ & $1570 \mathrm{~cm}^{-1}$ & $1570 \mathrm{~cm}^{-1}$ \\
\hline $\begin{array}{l}\text { D1 band (graphitic } \\
\text { hydrocarbons) }\end{array}$ & $1355 \mathrm{~cm}^{-1}$ & $1355 \mathrm{~cm}^{-1}$ \\
\hline $\mathrm{CH}_{2}$ vibrations & $1260 \mathrm{~cm}^{-1}$ & $1260 \mathrm{~cm}^{-1}$ \\
\hline \multicolumn{3}{|c|}{ FTIR spectroscopy } \\
\hline alkene & $\begin{array}{c}1613 ; \\
1626 \mathrm{~cm}^{-1}\end{array}$ & \\
\hline $\begin{array}{l}(\mathrm{O}-\mathrm{H} \text { stretching }) /(\mathrm{N}- \\
\mathrm{H} \text { stretching })\end{array}$ & $\begin{array}{l}3215 ; 3485 \\
3598 \mathrm{~cm}^{-1}\end{array}$ & \\
\hline $\begin{array}{l}\text { hydroxyl }(\mathrm{O}-\mathrm{H} \\
\text { stretching })\end{array}$ & \multicolumn{2}{|r|}{$3670 ; 3710 \mathrm{~cm}^{-1}$} \\
\hline $\begin{array}{l}\text { aliphatic }(\mathrm{C}-\mathrm{H} \\
\text { stretching })\end{array}$ & \multirow{2}{*}{\multicolumn{2}{|c|}{$\begin{array}{c}2845 ; 2853 ; 2868 ; 2921 ; 2951 ; \\
2980 ; 3004 \mathrm{~cm}^{-1} \\
1013 ; 1030 ; 1055 \mathrm{~cm}^{-1}\end{array}$}} \\
\hline $\begin{array}{l}\text { alcohol }(\mathrm{C}-\mathrm{O} \\
\text { stretching })\end{array}$ & & \\
\hline hydration & \multicolumn{2}{|l|}{$\begin{array}{l}530 ; 1634 ; \\
3360 \mathrm{~cm}^{-1}\end{array}$} \\
\hline
\end{tabular}

Additionally, for the FW- and eqFW-aged calcite samples, the IR spectra present certain hydration bands, which are not observed for the reference specimen (Figure S9). Since all analytes undergo heat treatment prior to spectral acquisition, the persistence of hydration bands is indicative of structural water typically associated with amorphous carbonate minerals. ${ }^{70}$ In contrast, for eqCRO-aged calcite, the IR spectrum exhibits weak peaks corresponding to $-\mathrm{OH}$ stretching at 3670 and $3710 \mathrm{~cm}^{-1}$, indicative of surface hydroxide species. The lack of distinct hydration bands suggests the destabilization (dissolution or crystallization) of amorphous minerals either on exposure to eqCRO or during solvent cleaning. Such metastable amorphous carbonate phases might play a role in the surface modification of minerals by high-salinity brines in reservoirs.

To further validate this evidence for amorphous mineral production in formation water, we also performed Raman spectroscopy on precipitates formed at $95{ }^{\circ} \mathrm{C}$ in eqFW without immersed calcite. Precipitates formed in eqFW are collected by centrifugation and Raman spectra are acquired in a wet state. 
Shown in Figure 5, the peak at $1082 \mathrm{~cm}^{-1}$ indicates the presence of amorphous calcium carbonate (ACC) with about (a)

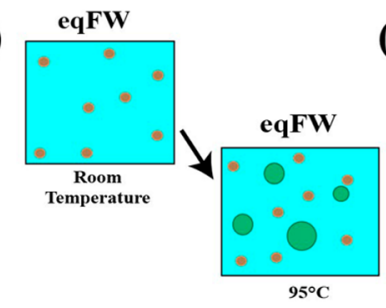

(b)

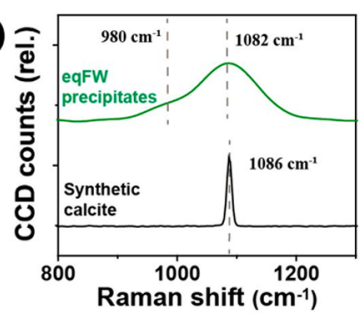

Figure 5. (a) Schematic depiction of precipitation (green) in the presence of CRO-derived organic molecules (brown) in eqFW after $16 \mathrm{~h}$ at $95{ }^{\circ} \mathrm{C}$. (b) Representative Raman spectrum of precipitates (green) indicative of amorphous calcium carbonate $\left(1082 \mathrm{~cm}^{-1}\right)$ and synthetic calcite (black).

$10 \mathrm{~mol} \% \mathrm{MgCO}_{3} \cdot{ }^{71}$ Since $\mathrm{Mg}^{2+}$ ions can enhance the stability of ACC, ${ }^{72}$ the ionic composition of FW (Table S1) with a high $\mathrm{Mg}^{2+} / \mathrm{Ca}^{2+}$ ratio of about 3 might explain the presence of amorphous minerals. In addition, the shoulder at $980 \mathrm{~cm}^{-1}$ suggests the coassociation of $\mathrm{SO}_{4}{ }^{2-}$ ions with the ACC particles, possibly as $\mathrm{MgSO}_{4(\mathrm{aq})}$ species. ${ }^{73}$ In this respect, the incorporation of $\mathrm{Mg}^{2+}$ ions in solute clusters and amorphous precursors during mineralization reactions is reported. ${ }^{74,75}$ This hints toward the rich dynamics of inorganic species in the form of ion pairs and metastable mineral precursors contributing to the surface modification of minerals in reservoirs. This might have ramifications toward the roles of ions like $\mathrm{Mg}^{2+}$ and $\mathrm{SO}_{4}{ }^{2-}$ in low-salinity $\mathrm{IOR}^{76}$

Besides the mentioned contributions toward the chemical modification of calcite (Figure 3), organic molecules in eqFW appear to interact with ionic species in brines and modulate mineralization. For instance, for mineral particles formed in unaged FW at $95{ }^{\circ} \mathrm{C}$, the Raman peak at $980 \mathrm{~cm}^{-1}$ indicative of $\mathrm{MgSO}_{4(\mathrm{aq})}$ species is absent (Figure 5; Figure S11). The organic molecules might thus mediate the stabilization of ion complexes. The same Raman spectrum also shows peaks at 210 and $701 \mathrm{~cm}^{-1}$ indicative of aragonite, a crystalline polymorph of calcium carbonate (Figure S11). In view of the lack of aragonite formation after eqFW treatment (Figure 2), the CRO-derived organic molecules appear to induce a polymorph selection toward calcite. Further evidence comes from the $x-y$ distribution maps of Iceland spar aged in $\mathrm{FW}$ at $95{ }^{\circ} \mathrm{C}$ (Figure $\mathrm{S} 12$ ), wherein aragonite is indeed present in the form of the characteristic rod-like crystals. The interactions of organic species with ion complexes and metastable mineral phases emerge as an interesting concept for the organic-inorganic interplay in reservoir conditions and requires further investigations.

Topographical Transitions of Calcite: Atomic Force Microscopy. AFM reveals changes of the micro- and nanoscale topography upon aging in eqFW and eqCRO at $95{ }^{\circ} \mathrm{C}$. As depicted in Figure 6a, the freshly cleaved (10.4) surface of the Iceland spar presents macrosteps with heights of $10-20 \mathrm{~nm}$, corresponding to bunches of a few tens monatomic steps $\left(\sim 3 \AA\right.$ for a monolayer step $\left.^{77}\right)$. Root-mean-square (RMS) roughness is estimated at about $3 \mathrm{~nm}$ from representative scan areas, which exclude macrosteps. On aging in fresh FW, asperities appear on the surface, which increase the RMS roughness to about $20 \mathrm{~nm}$ (Figure 6b). In contrast, aging in eqFW leads a roughness of merely $6 \mathrm{~nm}$ RMS (Figure 6c). The organic solutes present in eqFW thus seem to suppress surface reconstruction (including the growth of asperities) in a similar manner as capping agents during the synthesis of nanocrystals.

The asperities observed after aging in either FW or eqFW represent mineral overgrowth layers formed at high temperature due to the retrograde solubility of calcite. ${ }^{60}$ To estimate the extent of surface reconstruction (i.e., the average height difference), we protected calcite substrates partially by a sacrificial PDMS film during the aging (Figure S13). Upon removing the protective coating after aging, AFM height maps show significantly between the protected and unprotected regions, confirming mineral overgrowth during aging (Figure S14). Remarkably, significant variations in mineral layer thickness are observed for replicate experiments (about 0.2$0.6 \mu \mathrm{m}$ for FW; $0.8-7 \mu \mathrm{m}$ for eqFW). We tentatively attribute these variations to the dependence of local crystal growth and dissolution rates on the surface distributions of steps, kinks, and etch pits. ${ }^{78}$ Nonetheless the enhanced thicknesses of
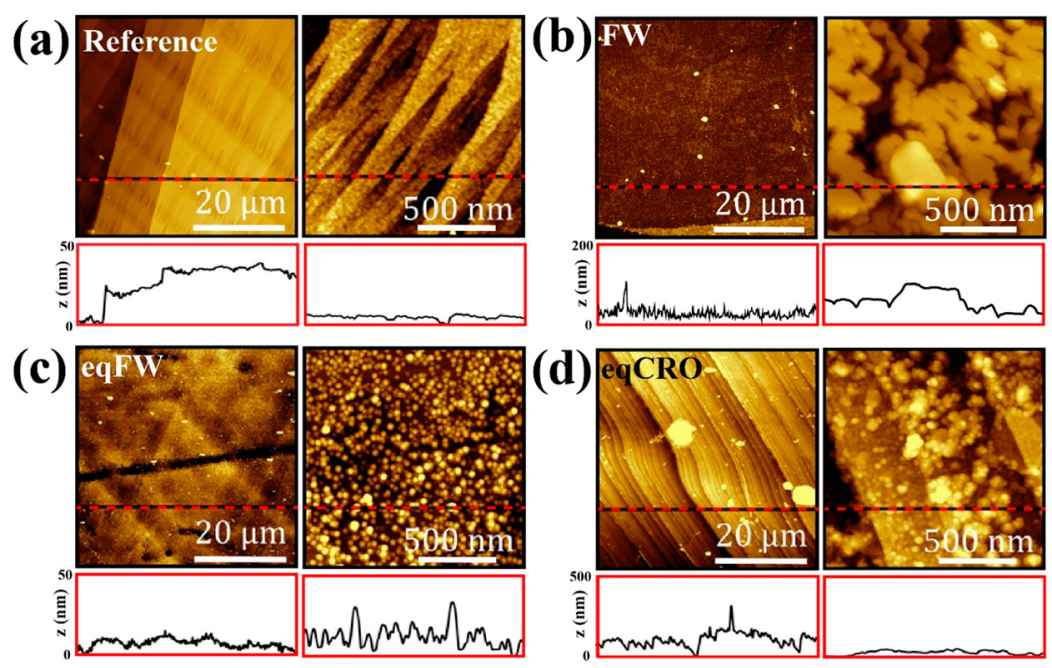

Figure 6. AFM height maps of surfaces in air for (a) reference Iceland spar and after aging in (b) fresh FW, (c) eqFW, and also (d) eqFW and eqCRO at scan areas of $50 \mu \mathrm{m} \times 50 \mu \mathrm{m}$ and $2 \mu \mathrm{m} \times 2 \mu \mathrm{m}$. Lower panels represent height profiles across the dotted red lines. 
mineral overgrowths in eqFW-aged crystals suggest that organic species influence the kinetics of mineral growth as well as contribute to the deposited mass, in agreement with the CRM-derived depth profiles of PAHs and fluorophores (Figure 4). Surface sorption and coprecipitation of organic species might thus serve as distinct pathways for the modification of reservoir minerals.

Although the composition of the mineral overgrowth layer is predominantly calcite, as shown by CRM (Figure 4), the heterogeneous constitution of FW (Table S1) can contribute toward some elemental partitioning between calcite and the brine. ${ }^{79}$ For instance, cationic or anionic substitutions might produce surface properties that deviate considerably from pristine calcite. ${ }^{80}$ Further, in view of the increased RMS roughness values of Iceland spar surfaces after FW or eqFW treatment, the nanoscale topographical features can play crucial roles in determining oil-brine-rock wetting behavior, thereby limiting the suitability of smooth "ideal" mineral surfaces in reservoir-related investigations.

To further investigate how crude oil alters the topography of eqFW-preconditioned mineral surfaces, AFM imaging was applied to eqCRO-aged calcite (Figure 6d). The surface features present lateral dimensions in the range $10 \mathrm{~nm}$ to $5 \mu \mathrm{m}$, wherein the morphology and distribution of adsorbates are indicative of asphaltenic aggregates. ${ }^{81}$ This is supported by chemical signatures of graphitic hydrocarbons in the corresponding Raman spectra (Figure 2). Nano- and microscale topographies of the surface adlayer for eqCRO-aged calcite are also evident from SEM micrographs (Figure 7). The scratch path is suggestive of a multilayer organization and the
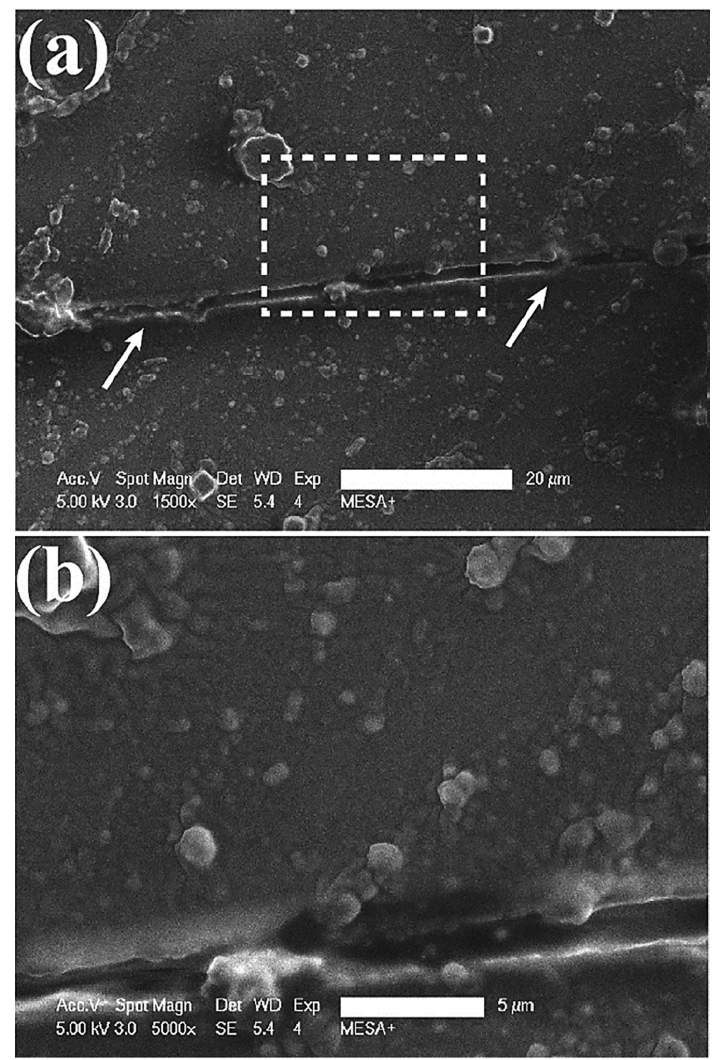

Figure 7. Scanning electron micrographs of eqCRO-aged calcite with scale bars representing (a) 20 and (b) $5 \mu \mathrm{m}$. (a) Scratch path across the surface (arrows) and the magnified region (box) are indicated. surface precipitation of organic molecules. Note that organic solvents applied during sample preparation can influence the morphology of organic deposits. ${ }^{81}$ Overall, the surface topography and chemistry of calcite undergo distinct transitions in relation to the applied aging fluids at elevated temperature. Associated fluid-minerals interactions can have key roles in determining the composition and structure of mineral and organic adlayers on reservoir rock surfaces. ${ }^{24}$

Microscopic Picture of Calcite Surface Modifications. By combining the above-described observations, we obtain further insights for mineral-brine-oil interactions in near reservoir environments. The surface modifications of calcite resulting from the two-step aging at $95{ }^{\circ} \mathrm{C}$ are categorized as topographical and chemical (Figure 8). Considering the topographical transitions, exposing the calcite to formation water (FW or eqFW) causes significant surface reconstruction on account of the retrograde solubility ${ }^{60}$ as well as the rich ionic composition of FW (Table S1). The magnitude of surface reconstruction is represented by the coverage of the Iceland spar substrate by nano- and micro-asperities (Figure 6), which appear primarily composed of calcite coassociated with hydrocarbons and amorphous minerals (Figure 4 and Figure 5). Preliminary geochemical analysis by using Visual MINTEQ shows that FW (see Table S1 for ionic composition) is supersaturated with respect to carbonate minerals, viz., calcite, aragonite, dolomite, and vaterite, at $95{ }^{\circ} \mathrm{C}$. Moreover aragonite precipitation is favored at elevated temperatures and with high $\mathrm{Mg}^{2+}$ ion contents, ${ }^{82}$ consistent with our CRM data of Iceland spar aged in fresh FW (Figure S12). In this respect, our results show that the reactions of mineral precipitation are regulated by the organic constituents of eqFW, viz., modulating ion association, controlling the growth of surface asperities, and mitigating the formation of aragonite. The topographical features of calcite crystals that emerge in CRO-equilibrated brines at elevated temperatures are thus dependent on (i) the ionic composition of aqueous phases, (ii) the abundance and chemical nature of organic molecules that undergo phase transfer from CRO, and (iii) conditions determining the solubility limit of carbonates (e.g., temperature ${ }^{60}$ ). In this regard, the chemistry of formation water is a key determinant of the morphologies and surface properties of minerals, also represented in the diagenetic alterations of minerals. ${ }^{66}$

On the contrary, the chemical alterations of calcite are relatively heterogeneous, attributed to characteristic features such as steps and kinks on the crystalline surface. Local rates of calcite dissolution or growth are substantial at these highenergy sites, which supports foreign entities to deposit on or incorporate within calcite crystals. ${ }^{62-64}$ This is evident from the $x-y$ distribution maps of PAHs and fluorophores for eqCRO-aged Iceland spar (Figure 2). In view of the lateral dimensions of organic aggregates in the range $10 \mathrm{~nm}$ to $5 \mu \mathrm{m}$ (Figure 6) and the reported values for surface coverage of calcite by PAHs (about $2.5-3.0 \mathrm{mg} / \mathrm{g}$ ), ${ }^{83}$ a continuous or multilayer type of sorption is prevalent. Involving poorly soluble metallo-organic species, mechanisms of the surface precipitation can contribute to the chemical modification of carbonate surfaces. ${ }^{84}$ This is also supported by previous reports of asphaltenes, which strongly bind to carbonates, presenting high contents of polar moieties such as carbonyl or carboxylic groups. $^{85}$

In this respect, formed during eqFW and eqCRO aging, the organic layers might represent a new surface phase and consist of poorly soluble organic and metallo-organic species. Taking 


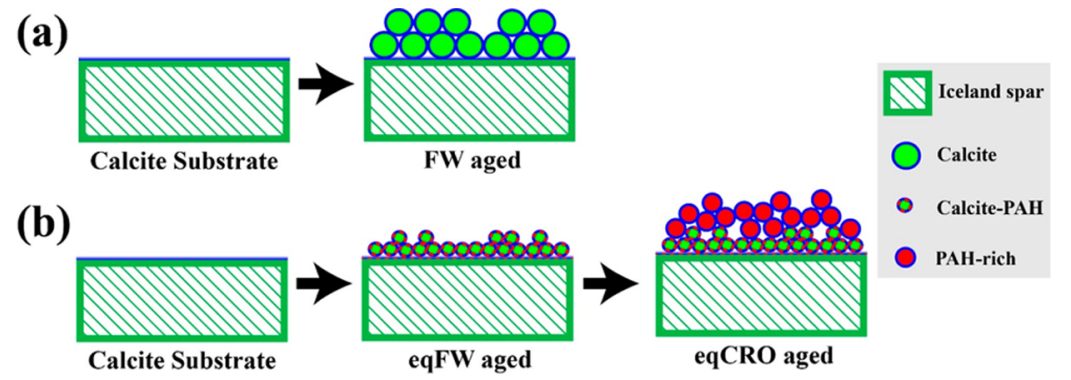

Figure 8. Schematic representation of the high-temperature modifications of Iceland spar substrate with either (a) pure FW or (b) sequential applications of eqFW and eqCRO. In brine environments, surface modification involves the deposition of particles composed of calcite and calcitePAH hybrids for aging in FW and eqFW, respectively. Organic molecules in eqFW regulate surface reconstruction events such as asperity growth. Upon further treatment with eqCRO, surface deposition of particles composed of PAHs such as asphaltenes occurs. Colors represent calcite (green), polyaromatic hydrocarbons (PAHs, red), and interfacial hydration (blue).

into consideration the geothermal gradients for the Earth's depth as well as the high dependence of the solubilities of carbonates $^{60}$ and metallo-organic salts on temperature and pressure conditions, the burial diagenesis of carbonate sediments emerges as a primary determinant of the chemical and topographical properties of carbonates. Consequences of these stepwise modifications on the surface wettability of Iceland spar are further addressed.

Wettability Alteration. Given the chemical and topographical heterogeneity of our aged calcite surfaces discussed above, we anticipate considerable contact angle (CA) hysteresis. ${ }^{65,86}$ In such cases, advancing $\left(\theta_{\text {oil }}^{\text {adv }}\right)$ and receding $\left(\theta_{\text {oil }}^{\text {rec }}\right)$ CAs rather than Young's angle are the only reliable measures of surface wettability. In all our experiments, strong pinning prevented any receding motion of the contact line and thus any measurement of a meaningful value of $\theta_{\text {oil }}^{\text {rec }}$. Measurements of $\theta_{\mathrm{oil}}^{\text {adv }}$ displayed a substantial spread even for nominally identical conditions, as expected in view of the surface heterogeneities (Figure 9). Nevertheless, a significant increase of $\theta_{\text {oil }}^{\text {adv }}$ is observed between freshly cleaved $\left(\theta_{\text {oil }}^{\text {adv }}=\right.$ $\left.112^{\circ}-136^{\circ}\right)$ and eqFW-aged $\left(125^{\circ}-146^{\circ}\right)$ samples. This variation can arise from two different effects: the deposition of organic species on the surface and the increase in surface

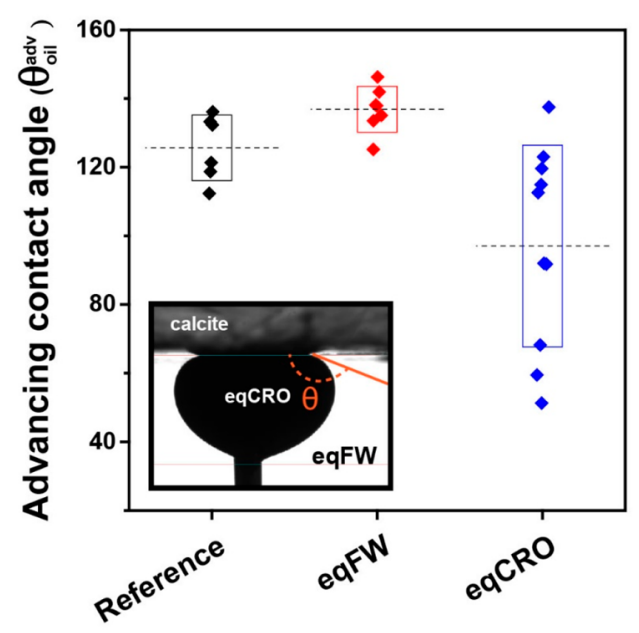

Figure 9. Box chart for distributions of oil side advancing contact angles $\left(\theta_{\text {oil }}^{\text {adv }}\right)$ for crude oil (eqCRO) droplets on Iceland spar substrate, freshly cleaved (reference, black), eqFW-aged (red), and eqCRO-aged (blue). Box-splitting horizontal dotted lines represent the mean values, and box range shows \pm 1 standard deviation. roughness. From the AFM images, we find that the roughness parameter $R=A_{\text {true }} / A_{\text {app }}$, i.e., the ratio between the true microscopic drop substrate interfacial area $A_{\text {true }}$ and the apparent geometric area $A_{\text {app}}$, is approximately 1.1. Using Wenzel's law, $\cos \theta_{\text {app }}=R \cos \theta_{\mathrm{Y}}$, we infer that the roughening accounts for approximately half of the observed contact angle variation. The second half must be then caused by adsorbing polar organic material that renders the surface chemically more water wet.

For mineral surfaces exposed to eqCRO, a broad distribution of $\theta_{\text {oil }}^{\text {adv }}$ values from about $51^{\circ}$ to $138^{\circ}$ is found, indicating more oil-wet behavior. At the same time, however, a much stronger hysteresis and a wider spread of $\theta_{\text {oil }}^{\text {adv }}$ is observed. The organic adlayer formed on exposure of the calcite to eqCRO is probably the primary determinant of the observed oil-wet nature. The heterogeneous surface distributions of aromatic molecules and fluorophores favored at sites of mineral reconstruction (Figure 2) could also account for the particularly widespread $\theta_{\mathrm{oil}}^{\text {adv }}$ as well as the large hysteresis. In comparison to relatively inert silica or clay substrates, the evolution and distribution of $\theta_{\mathrm{oil}}^{\mathrm{adv}}$ thus show that not only the deposition of organic molecules from equilibrated brines and CRO, but also the reconstruction of the mineral surface play important roles in controlling surface wettability.

\section{CONCLUSIONS}

Our work provides a clear picture of the microscopic alteration of calcite surfaces upon exposure to equilibrated fluids at elevated temperatures, giving rise to distinct modifications of both surface topography and chemistry. Calcite surfaces exposed to formation waters undergo reconstruction and exhibit high coverage by asperities consisting primarily of inorganic calcite. For samples aged in eqFW, chemical modifications involving aromatic and polar hydrocarbons are also evident. The organic material is not only deposited to the surface but becomes partly embedded in the mineral, demonstrating that both organic and inorganic species contribute to the surface reconstruction of carbonates. At the macroscale, these modifications are rather heterogeneous due to their sensitivity to local variations of multiple factors including fluctuations in composition of the ambient fluids, in substrate quality (high-energy sites, crystal defects) and-at least in oil reservoirs -in geothermal gradients.

On contact with eqCRO, surface deposition of organic layers occurs, presenting morphologies and chemical signatures consistent with those of asphaltenic particles. Resultant of 
sorption events and surface precipitation, this organic layer primarily determines the oil-wet behavior of aged calcite. Since this $\mathrm{PAH}$-enriched layer forms upon prolonged aging at elevated temperatures, conditions such as ambient fluid compositions and temperature are essential in controlling and, hence, also in replicating the properties for petroleum engineering experiments. ${ }^{36,37}$ The chemical and topographical differences of the mineral overgrowth from the freshly cleaved Iceland spar surface also brings into question the representativeness of pristine surfaces for studying wettability and wettability alteration in carbonate reservoirs.

In all, the sequential aging of calcite in reservoir pertinent fluids at high temperature produces mineral overgrowths and organic adlayers that isolate the initially pristine crystal surfaces from the crude oil and thus control the wettability of the resulting aged surface. Hence, we anticipate that the responsivity of these mineral and organic adlayers to injection fluids of variable compositions is crucial to the success of IOR strategies.

\section{ASSOCIATED CONTENT}

\section{(s) Supporting Information}

The Supporting Information is available free of charge at https://pubs.acs.org/doi/10.1021/acs.energyfuels.0c00118.

Tables of composition and geochemical analysis of synthetic formation water, band and peak position assignments, and IR band frequencies and figures of schematic representations, illustration of postprocessing steps, IR spectra, absorbance spectra, light microscopy images, Raman spectra, XPS spectra, CRM-derived false color maps, FTIR spectra, curve fittings of IR spectral regions, and AFM height maps (PDF)

\section{AUTHOR INFORMATION}

\section{Corresponding Authors}

Ashit Rao - Physics of Complex Fluids Group and MESA+ Institute, Faculty of Science and Technology, University of Twente, 7500 AE Enschede, The Netherlands; (1) orcid.org/ 0000-0002-5440-8007; Email: A.R.Rao@utwente.nl

Frieder Mugele - Physics of Complex Fluids Group and MESA + Institute, Faculty of Science and Technology, University of Twente, 7500 AE Enschede, The Netherlands; Email: F.Mugele@utwente.nl

\section{Authors}

Saravana Kumar - Physics of Complex Fluids Group and MESA+ Institute, Faculty of Science and Technology, University of Twente, 7500 AE Enschede, The Netherlands

Carla Annink - Physics of Complex Fluids Group and MESA+ Institute, Faculty of Science and Technology, University of Twente, 7500 AE Enschede, The Netherlands

Duy Le-Anh - Physics of Complex Fluids Group and MESA+ Institute, Faculty of Science and Technology, University of Twente, 7500 AE Enschede, The Netherlands

Subhash C. Ayirala - The Exploration and Petroleum Engineering Center - Advanced Research Center (EXPEC ARC), Saudi Aramco, Dhahran 34465, Saudi Arabia

Mohammed B. Alotaibi - The Exploration and Petroleum Engineering Center - Advanced Research Center (EXPEC ARC), Saudi Aramco, Dhahran 34465, Saudi Arabia

Igor Siretanu - Physics of Complex Fluids Group and MESA+ Institute, Faculty of Science and Technology, University of
Twente, 7500 AE Enschede, The Netherlands; ㅇoㅇi.org/ 0000-0002-5741-9561

Michel H.G. Duits - Physics of Complex Fluids Group and MESA+ Institute, Faculty of Science and Technology, University of Twente, 7500 AE Enschede, The Netherlands; $\odot$ orcid.org/ 0000-0003-1412-4955

Ali A. Yousef - The Exploration and Petroleum Engineering Center - Advanced Research Center (EXPEC ARC), Saudi Aramco, Dhahran 34465, Saudi Arabia

Complete contact information is available at: https://pubs.acs.org/10.1021/acs.energyfuels.0c00118

\section{Notes}

The authors declare no competing financial interest.

\section{REFERENCES}

(1) Klemme, H.; Ulmishek, G. F. Effective petroleum source rocks of the world: stratigraphic distribution and controlling depositional factors (1). AAPG Bull. 1991, 75 (12), 1809-1851.

(2) Schulte, W. M. Challenges and strategy for increased oil recovery. International Petroleum Technology Conference, Doha, Qatar, Nov 21-25, 2005; Society of Petroleum Engineers.

(3) Cantrell, D. L.; Hagerty, R. M. Microporosity in arab formation carbonates, Saudi Arabia. GeoArabia 1999, 4 (2), 129-154.

(4) Kovscek, A.; Wong, H.; Radke, C. A pore-level scenario for the development of mixed wettability in oil reservoirs. AIChE J. 1993, 39 (6), 1072-1085.

(5) Treiber, L.; Owens, W. A laboratory evaluation of the wettability of fifty oil-producing reservoirs. SPEJ, Soc. Pet. Eng. J. 1972, 12 (06), 531-540.

(6) Kaminsky, R.; Radke, C. Asphaltenes, water films, and wettability reversal. SPE Journal 1997, 2 (04), 485-493.

(7) Derkani, M.; Fletcher, A.; Abdallah, W.; Sauerer, B.; Anderson, J.; Zhang, Z. Low salinity waterflooding in carbonate reservoirs: review of interfacial mechanisms. Colloids and Interfaces 2018, 2 (2), 20.

(8) Yousef, A. A.; Al-Saleh, S. H.; Al-Kaabi, A.; Al-Jawfi, M. S. Laboratory investigation of the impact of injection-water salinity and ionic content on oil recovery from carbonate reservoirs. SPE Reservoir Evaluation \& Engineering 2011, 14 (05), 578-593.

(9) Muggeridge, A.; Cockin, A.; Webb, K.; Frampton, H.; Collins, I.; Moulds, T.; Salino, P. Recovery rates, enhanced oil recovery and technological limits. Philos. Trans. R. Soc., A 2014, 372 (2006), 20120320.

(10) Hiorth, A.; Cathles, L.; Madland, M. The impact of pore water chemistry on carbonate surface charge and oil wettability. Transp. Porous Media 2010, 85 (1), 1-21.

(11) Lashkarbolooki, M.; Riazi, M.; Hajibagheri, F.; Ayatollahi, S. Low salinity injection into asphaltenic-carbonate oil reservoir, mechanistical study. J. Mol. Liq. 2016, 216, 377-386.

(12) Fathi, S. J.; Austad, T.; Strand, S. Water-based enhanced oil recovery (EOR) by "smart water": Optimal ionic composition for EOR in carbonates. Energy Fuels 2011, 25 (11), 5173-5179.

(13) Austad, T.; Shariatpanahi, S.; Strand, S.; Black, C.; Webb, K. Conditions for a low-salinity enhanced oil recovery (EOR) effect in carbonate oil reservoirs. Energy Fuels 2012, 26 (1), 569-575.

(14) Jackson, M. D.; Al-Mahrouqi, D.; Vinogradov, J. Zeta potential in oil-water-carbonate systems and its impact on oil recovery during controlled salinity water-flooding. Sci. Rep. 2016, 6, 37363.

(15) Mahani, H.; Keya, A. L.; Berg, S.; Bartels, W.-B.; Nasralla, R.; Rossen, W. R. Insights into the mechanism of wettability alteration by low-salinity flooding (LSF) in carbonates. Energy Fuels 2015, 29 (3), $1352-1367$

(16) Zhang, P.; Austad, T. Wettability and oil recovery from carbonates: Effects of temperature and potential determining ions. Colloids Surf., A 2006, 279 (1-3), 179-187. 
(17) Yutkin, M. P.; Mishra, H.; Patzek, T. W.; Lee, J.; Radke, C. J. Bulk and surface aqueous speciation of calcite: implications for lowsalinity waterflooding of carbonate reservoirs. SPE Journal 2018, 23, 084.

(18) Chen, S.-Y.; Kaufman, Y.; Kristiansen, K.; Seo, D.; Schrader, A. M.; Alotaibi, M. B.; Dobbs, H. A.; Cadirov, N. A.; Boles, J. R.; Ayirala, S. C.; et al. Effects of salinity on oil recovery (the "Dilution Effect"): Experimental and theoretical studies of crude oil/brine/carbonate surface restructuring and associated physicochemical interactions. Energy Fuels 2017, 31 (9), 8925-8941.

(19) Larter, S.; Aplin, A.; Corbett, P. W. M.; Ementon, N.; Chen, M.; Taylor, P. Reservoir geochemistry: A link between reservoir geology and engineering? SPE Reservoir Eng. 1997, 12 (01), 12-17.

(20) Benzagouta, M. S.; Amro, M. M. Pressure and temperature effect on petrophysical characteristics: Carbonate reservoir case. SPE Saudi Arabia Section Technical Symposium, Khobar, Saudi Arabia, May 9-11, 2009; Society of Petroleum Engineers.

(21) Putnis, A. Mineral replacement reactions. Rev. Mineral. Geochem. 2009, 70 (1), 87-124.

(22) Ruiz-Agudo, E.; Putnis, C. Direct observations of mineral-fluid reactions using atomic force microscopy: the specific example of calcite. Mineral. Mag. 2012, 76 (1), 227-253.

(23) Gillet, P.; Biellmann, C.; Reynard, B.; McMillan, P. Raman spectroscopic studies of carbonates Part I: High-pressure and hightemperature behaviour of calcite, magnesite, dolomite and aragonite. Phys. Chem. Miner. 1993, 20 (1), 1-18.

(24) Ivanova, A.; Mitiurev, N.; Cheremisin, A.; Orekhov, A.; Kamyshinsky, R.; Vasiliev, A. Characterization of organic Layer in oil Carbonate Reservoir Rocks and its Effect on Microscale Wetting properties. Sci. Rep. 2019, 9 (1), 1-10.

(25) Cölfen, H. Precipitation of carbonates: recent progress in controlled production of complex shapes. Curr. Opin. Colloid Interface Sci. 2003, 8 (1), 23-31.

(26) Rodriguez-Navarro, C.; Benning, L. G. Control of crystal nucleation and growth by additives. Elements 2013, 9 (3), 203-209.

(27) Beens, J.; Blomberg, J.; Schoenmakers, P. J. Proper tuning of comprehensive two-dimensional gas chromatography (GCX GC) to optimize the separation of complex oil fractions. J. High Resolut. Chromatogr. 2000, 23 (3), 182-188.

(28) Mullins, O. C.; Betancourt, S. S.; Cribbs, M. E.; Dubost, F. X.; Creek, J. L.; Andrews, A. B.; Venkataramanan, L. The colloidal structure of crude oil and the structure of oil reservoirs. Energy Fuels 2007, 21 (5), 2785-2794.

(29) Marshall, A. G.; Rodgers, R. P. Petroleomics: Chemistry of the underworld. Proc. Natl. Acad. Sci. U. S. A. 2008, 105 (47), 1809018095.

(30) Joonaki, E.; Buckman, J.; Burgass, R.; Tohidi, B. Water versus Asphaltenes; Liquid-Liquid and Solid-Liquid Molecular Interactions Unravel the Mechanisms behind an Improved Oil Recovery Methodology. Sci. Rep. 2019, 9 (1), 1-13.

(31) Eftekhardadkhah, M.; Kløcker, K. N.; Trapnes, H. H.; Gaweł, B.; Øye, G. Composition and dynamic adsorption of crude oil components dissolved in synthetic produced water at different $\mathrm{pH}$ values. Ind. Eng. Chem. Res. 2016, 55 (11), 3084-3090.

(32) Hutin, A.; Argillier, J.-F. o.; Langevin, D. Mass transfer between crude oil and water. Part 1: Effect of oil components. Energy Fuels 2014, 28 (12), 7331-7336.

(33) Haagh, M. E.; Schilderink, N.; Mugele, F.; Duits, M. H. Wetting of mineral surfaces by fatty-acid laden oil and brine: carbonate effect at elevated temperature. Energy Fuels 2019, 33, 9446.

(34) Sjöblom, J.; Simon, S.; Xu, Z. Model molecules mimicking asphaltenes. Adv. Colloid Interface Sci. 2015, 218, 1-16.

(35) Tabrizy, V. A.; Denoyel, R.; Hamouda, A. Characterization of wettability alteration of calcite, quartz and kaolinite: Surface energy analysis. Colloids Surf., A 2011, 384 (1-3), 98-108.

(36) Hirasaki, G.; Zhang, D. L. Surface chemistry of oil recovery from fractured, oil-wet, carbonate formations. Spe Journal 2004, 9 (02), 151-162.
(37) Yu, L.; Buckley, J. Evolution of wetting alteration by adsorption from crude oil. SPE Form. Eval. 1997, 12 (01), 5-12.

(38) Neff, J.; Anderson, J. An ultraviolet spectrophotometric method for the determination of naphthalene and alkylnaphthalenes in the tissues of oil-contaminated marine animals. Bull. Environ. Contam. Toxicol. 1975, 14 (1), 122-128.

(39) Evans, C. H.; Partyka, M.; Van Stam, J. Naphthalene complexation by $\beta$-cyclodextrin: influence of added short chain branched and linear alcohols. J. Inclusion Phenom. Mol. Recognit. Chem. 2000, 38 (1-4), 381-396.

(40) Shiu, W. Y.; Bobra, M.; Bobra, A. M.; Maijanen, A.; Suntio, L.; Mackay, D. The water solubility of crude oils and petroleum products. Oil Chem. Pollut. 1990, 7 (1), 57-84.

(41) Sau, S.; Solanki, B.; Orprecio, R.; Van Stam, J.; Evans, C. H. Higher-order cyclodextrin complexes: The naphthalene system. J. Inclusion Phenom. Mol. Recognit. Chem. 2004, 48 (3-4), 173-180.

(42) Das, S.; Sahana, A.; Lohar, S.; Sarkar, B.; Mukhopadhya, S. K.; Banerjee, A.; Das, D. A visible light excitable pyrene-naphthalene conjugate for ON fluorescence sensing of histidine in living cells. RSC Adv. 2014, 4 (15), 7495-7499.

(43) Boehm, P. D.; Quinn, J. G. Solubilization of hydrocarbons by the dissolved organic matter in sea water. Geochim. Cosmochim. Acta 1973, 37 (11), 2459-2477.

(44) Tanaka, S.; Oba, K.; Fukushima, M.; Nakayasu, K.; Hasebe, K. Water solubility enhancement of pyrene in the presence of humic substances. Anal. Chim. Acta 1997, 337 (3), 351-357.

(45) Khuwijitjaru, P.; Adachi, S.; Matsuno, R. Solubility of saturated fatty acids in water at elevated temperatures. Biosci., Biotechnol., Biochem. 2002, 66 (8), 1723-1726.

(46) Al-Nofli, K.; Pourafshary, P.; Mosavat, N.; Shafiei, A. Effect of initial wettability on performance of smart water flooding in carbonate reservoirs-an experimental investigation with ior implications. Energies 2018, 11 (6), 1394.

(47) Gunasekaran, S.; Anbalagan, G.; Pandi, S. Raman and infrared spectra of carbonates of calcite structure. J. Raman Spectrosc. 2006, 37 (9), 892-899.

(48) Jawhari, T.; Roid, A.; Casado, J. Raman spectroscopic characterization of some commercially available carbon black materials. Carbon 1995, 33 (11), 1561-1565.

(49) Cancado, L.; Pimenta, M.; Neves, B.; Dantas, M.; Jorio, A. Influence of the atomic structure on the Raman spectra of graphite edges. Phys. Rev. Lett. 2004, 93 (24), 247401.

(50) Colthup, N. Introduction to infrared and Raman spectroscopy; Academic Press, 1990.

(51) Riedeman, J. S.; Kadasala, N. R.; Wei, A.; Kenttämaa, H. I. Characterization of asphaltene deposits by using mass spectrometry and Raman spectroscopy. Energy Fuels 2016, 30 (2), 805-809.

(52) Abdallah, W. A.; Yang, Y. Raman spectrum of asphaltene. Energy Fuels 2012, 26 (11), 6888-6896.

(53) Andreatta, G.; Goncalves, C. C.; Buffin, G.; Bostrom, N.; Quintella, C. M.; Arteaga-Larios, F.; Pérez, E.; Mullins, O. C. Nanoaggregates and structure- function relations in asphaltenes. Energy Fuels 2005, 19 (4), 1282-1289.

(54) Aske, N.; Kallevik, H.; Johnsen, E. E.; Sjöblom, J. Asphaltene aggregation from crude oils and model systems studied by highpressure NIR spectroscopy. Energy Fuels 2002, 16 (5), 1287-1295.

(55) Saraji, S.; Goual, L.; Piri, M. Dynamic adsorption of asphaltenes on quartz and calcite packs in the presence of brine films. Colloids Surf., A 2013, 434, 260-267.

(56) Marczewski, A. W.; Szymula, M. Adsorption of asphaltenes from toluene on mineral surface. Colloids Surf., A 2002, 208 (1-3), 259-266.

(57) Stipp, S. L.; Hochella, M. F., Jr Structure and bonding environments at the calcite surface as observed with X-ray photoelectron spectroscopy (XPS) and low energy electron diffraction (LEED). Geochim. Cosmochim. Acta 1991, 55 (6), 17231736. 
(58) Mason, R.; Mariano, A. Cathodoluminescence activation in manganese-bearing and rare earth-bearing synthetic calcites. Chem. Geol. 1990, 88 (1-2), 191-206.

(59) Nair, S.; Gao, J.; Yao, Q.; Duits, M. H.; Otto, C.; Mugele, F. Algorithm-improved high speed and non-invasive confocal Raman imaging of two-dimensional materials. National Science Review 2019.

(60) Plummer, L. N.; Busenberg, E. The solubilities of calcite, aragonite and vaterite in $\mathrm{CO} 2-\mathrm{H} 2 \mathrm{O}$ solutions between 0 and $90 \mathrm{C}$, and an evaluation of the aqueous model for the system $\mathrm{CaCO} 3-\mathrm{CO} 2-$ H2O. Geochim. Cosmochim. Acta 1982, 46 (6), 1011-1040.

(61) Strausz, O. P.; Safarik, I.; Lown, E. M. Cause of asphaltene fluorescence intensity variation with molecular weight and its ramifications for laser ionization mass spectrometry. Energy Fuels 2009, 23 (3), 1555-1562.

(62) Gratz, A. J.; Hillner, P. E. Poisoning of calcite growth viewed in the atomic force microscope (AFM). J. Cryst. Growth 1993, 129 (34), 789-793.

(63) Nielsen, L. C.; De Yoreo, J. J.; DePaolo, D. J. General model for calcite growth kinetics in the presence of impurity ions. Geochim. Cosmochim. Acta 2013, 115, 100-114.

(64) Magnabosco, G.; Polishchuk, I.; Palomba, F.; Rampazzo, E.; Prodi, L.; Aizenberg, J.; Pokroy, B.; Falini, G. Role of surface chemistry on incorporation of nanoparticles within calcite single crystals. Cryst. Growth Des. 2019, 19, 4429.

(65) Salathiel, R. Oil recovery by surface film drainage in mixedwettability rocks. JPT, J. Pet. Technol. 1973, 25 (10), 1216-1224.

(66) Dravis, J. J.; Yurewicz, D. A. Enhanced carbonate petrography using fluorescence microscopy. J. Sediment. Res. 1985, 55 (6), 795804.

(67) Wood, S.; Hollis, J. R.; Kim, J.-S. Raman spectroscopy as an advanced structural nanoprobe for conjugated molecular semiconductors. J. Phys. D: Appl. Phys. 2017, 50 (7), 073001.

(68) Coates, J. Interpretation of infrared spectra, a practical approach. Encyclopedia of analytical chemistry: applications, theory and instrumentation; John Wiley \& Sons, Ltd.: Chichester, UK, 2006.

(69) Coelho, R. R.; Hovell, I.; Moreno, E. L.; de Souza, A. L.; Rajagopal, K. Characterization of functional groups of asphaltenes in vacuum residues using molecular modelling and FTIR techniques. Pet. Sci. Technol. 2007, 25 (1-2), 41-54.

(70) Michel, F. M.; MacDonald, J.; Feng, J.; Phillips, B. L.; Ehm, L.; Tarabrella, C.; Parise, J. B.; Reeder, R. J. Structural characteristics of synthetic amorphous calcium carbonate. Chem. Mater. 2008, 20 (14), $4720-4728$.

(71) Wang, D.; Hamm, L. M.; Bodnar, R. J.; Dove, P. M. Raman spectroscopic characterization of the magnesium content in amorphous calcium carbonates. J. Raman Spectrosc. 2012, 43 (4), $543-548$.

(72) Loste, E.; Wilson, R. M.; Seshadri, R.; Meldrum, F. C. The role of magnesium in stabilising amorphous calcium carbonate and controlling calcite morphologies. J. Cryst. Growth 2003, 254 (1-2), 206-218.

(73) Rudolph, W.; Irmer, G.; Hefter, G. Raman spectroscopic investigation of speciation in $\mathrm{MgSO} 4$ (aq). Phys. Chem. Chem. Phys. 2003, 5 (23), 5253-5261.

(74) Wolf, S. L.; Jähme, K.; Gebauer, D. Synergy of Mg 2+ and poly (aspartic acid) in additive-controlled calcium carbonate precipitation. CrystEngComm 2015, 17 (36), 6857-6862.

(75) Verch, A.; Antonietti, M.; Cölfen, H. Mixed calciummagnesium pre-nucleation clusters enrich calcium. Z. Kristallogr. Cryst. Mater. 2012, 227 (11), 718-722.

(76) Strand, S.; Høgnesen, E. J.; Austad, T. Wettability alteration of carbonates-Effects of potential determining ions (Ca2+ and SO42-) and temperature. Colloids Surf., A 2006, 275 (1-3), 1-10.

(77) Vavouraki, A. I.; Putnis, C. V.; Putnis, A.; Koutsoukos, P. G. An Atomic Force Microscopy study of the growth of calcite in the presence of sodium sulfate. Chem. Geol. 2008, 253 (3-4), 243-251. (78) Arvidson, R. S.; Ertan, I. E.; Amonette, J. E.; Luttge, A. Variation in calcite dissolution rates: A fundamental problem? Geochim. Cosmochim. Acta 2003, 67 (9), 1623-1634.
(79) Gabitov, R.; Sadekov, A.; Yapaskurt, V.; Borrelli, C.; Bychkov, A.; Sabourin, K.; Perez-Huerta, A. Elemental uptake by calcite slowly grown from seawater solution: an in-situ study via depth profiling. Frontiers in Earth Science 2019, 7, 51.

(80) Andersson, M. P.; Dideriksen, K.; Sakuma, H.; Stipp, S. L. S. Modelling how incorporation of divalent cations affects calcite wettability-implications for biomineralisation and oil recovery. Sci. Rep. 2016, 6, 28854.

(81) Kumar, K.; Dao, E.; Mohanty, K. AFM study of mineral wettability with reservoir oils. J. Colloid Interface Sci. 2005, 289 (1), 206-217.

(82) Fermani, S.; Džakula, B. N.; Reggi, M.; Falini, G.; Kralj, D. Effects of magnesium and temperature control on aragonite crystal aggregation and morphology. CrystEngComm 2017, 19 (18), 24512455.

(83) González, G.; Middea, A. The properties of the calcitesolution interface in the presence of adsorbed resins or asphaltenes. Colloids Surf. 1988, 33, 217-229.

(84) Comans, R. N.; Middelburg, J. J. Sorption of trace metals on calcite: Applicability of the surface precipitation model. Geochim. Cosmochim. Acta 1987, 51 (9), 2587-2591.

(85) Subramanian, S.; Sørland, G. H.; Simon, S.; Xu, Z.; Sjöblom, J. Asphaltene fractionation based on adsorption onto calcium carbonate: Part 2. Self-association and aggregation properties. Colloids Surf., A 2017, 514, 79-90.

(86) Sari, A.; Al Maskari, N. S.; Saeedi, A.; Xie, Q. Impact of surface roughness on wettability of oil-brine-calcite system at sub-pore scale. J. Mol. Liq. 2020, 299, 112107. 